\title{
Enhanced anti-inflammatory potential of cinnamate-zinc layered hydroxide in lipopolysaccharide-stimulated RAW 264.7 macrophages
}

\author{
This article was published in the following Dove Press journal: \\ Drug Design, Development and Therapy \\ 30 April 2015 \\ Number of times this article has been viewed
}

\author{
Malik Adewoyin' \\ Sumaiyah Megat Nabil \\ Mohsin ${ }^{2}$ \\ Palanisamy Arulselvan' \\ Mohd Zobir Hussein ${ }^{2}$ \\ Sharida Fakurazi ${ }^{1,3}$ \\ 'Laboratory of Vaccines and \\ Immunotherapeutics, Institute \\ of Bioscience, ${ }^{2}$ Materials Synthesis \\ and Characterization Laboratory, \\ Institute of Advanced Technology, \\ ${ }^{3}$ Faculty of Medicine and Health \\ Sciences, Pharmacology Unit, \\ Universiti Putra Malaysia, Selangor, \\ Malaysia
}

\begin{abstract}
Background: Cinnamic acid (CA) is a phytochemical originally derived from Cinnamomum cassia, a plant with numerous pharmacological properties. The intercalation of CA with a nanocarrier, zinc layered hydroxide, produces cinnamate-zinc layered hydroxide (ZCA), which has been previously characterized. Intercalation is expected to improve the solubility and cell specificity of CA. The nanocarrier will also protect CA from degradation and sustain its release. The aim of this study was to assess the effect of intercalation on the anti-inflammatory capacity of CA.
\end{abstract}

Methods: In this study, the anti-inflammatory activity of ZCA was investigated and compared with that of nonintercalated CA. Evaluations were based on the capacity of ZCA and CA to modulate the release of nitric oxide, prostaglandin $\mathrm{E}_{2}$, interleukin (IL)-6, tumor necrosis factor alpha (TNF- $\alpha$ ), IL-1 $\beta$, and IL-10 in lipopolysaccharide-induced RAW 264.7 cells. Additionally, the expression of proinflammatory enzymes, ie, cyclooxygenase-2, inducible nitric oxide synthase, and nuclear factor kappa B (NF- $\mathrm{BB})$, were examined.

Results: Although both ZCA and CA downregulated nitric oxide, prostaglandin $\mathrm{E}_{2}$, tumor necrosis factor alpha, IL-1 $\beta$, and IL-6, ZCA clearly displayed better activity. Similarly, expression of cyclooxygenase- 2 and inducible nitric oxide synthase were inhibited in samples treated with ZCA and CA. The two compounds effectively inactivated the transcription factor NF- $\mathrm{kB}$, but the anti-inflammatory cytokine, IL-10, was significantly upregulated by ZCA only.

Conclusion: The present findings suggest that ZCA possesses better anti-inflammatory potential than CA, while zinc layered hydroxide had little or no effect, and these results were comparable with the positive control.

Keywords: cinnamic acid, zinc layered hydroxide, inflammation, RAW 264.7 cells

\section{Introduction}

Inflammation is a beneficial host response to foreign attack or tissue injury that eventually leads to restoration of normal tissue structure and function. ${ }^{1,2}$ Acute inflammation is a controlled beneficial process, especially in response to infectious agents, but chronic inflammation is an obnoxious persistent phenomenon that may result in inflammatory disease. ${ }^{3,4}$ Detection of invaders through a wide range of foreign molecular patterns, which induce initiation of the protective innate immunity and inflammatory process, encompasses the first line of the body's defense system. The major components of innate immunity are phagocytes (macrophages, neutrophils, and dendritic cells), complement system protein, and natural killer cells. ${ }^{5,6}$ Although the first immune cells
Correspondence: Sharida Fakurazi Faculty of Medicine and Health Sciences, and Laboratory of Vaccines and Immunotherapeutics, Institute of Bioscience, Universiti Putra Malaysia, 43400 UPM Serdang, Selangor, Malaysia

Tel +6038947233I

Fax +6038942 234I

Email sharida@upm.edu.my; sharida.fakurazi@gmail.com 
to reach an area of attack are the neutrophils, macrophages mastermind the activation of the inflammatory reaction. ${ }^{7,8}$

Macrophages and other activated inflammatory cells secrete high amounts of prostaglandin $\mathrm{PGE}_{2}\left(\mathrm{PGE}_{2}\right)$, nitric oxide (NO), and cytokines, such as interleukin (IL)-6, tumor necrosis factor alpha (TNF- $\alpha$ ), and IL-1 $\beta$. Undoubtedly, host defense is complemented by these mediators, and their uncontrolled production can be a factor in the pathogenesis of many diseases, such as rheumatoid arthritis, atherosclerosis, sepsis, and pulmonary fibrosis. ${ }^{9-11}$ They may also induce cell and tissue damage. ${ }^{12,13}$ Since the production of these soluble factors is associated with macrophages, they are considered to play a critical role during inflammation by managing various immunopathological phenomena. ${ }^{14,15}$ Likewise, the presence of these mediators in the macrophages of inflammatory tissues with increased expression of their mRNAs, following exposure to an inflammatory stimulus, has been proven. Thus, inhibiting the production of these mediators remains a critical target in combating inflammatory diseases. ${ }^{16,17}$

Cinnamomum cassia, an evergreen plant of the Lauraceae family, has long been associated with the treatment of inflammatory disease, dyspepsia, blood circulation disturbances, and gastritis. Its extracts contain phenolics such as cinnamic alcohol, cinnamic aldehyde, coumarin, and cinnamic acid (CA). ${ }^{18,19} \mathrm{CA}$ has recently demonstrated significant anti-inflammatory potential in both in vitro and in vivo experiments. ${ }^{20}$ Apart from its antioxidant properties, CA has been found to reduce cell proliferation by $50 \%$ in melanoma, glioblastoma, and lung and prostate carcinoma cells. ${ }^{21,22}$ The compound also displayed antidiabetic activity in insulin-resistant FL83B cells. ${ }^{23}$

Basically, the factors that determine the effect of a drug molecule are its natural therapeutic activity and its efficient delivery at the site of action. ${ }^{24,25}$ However, most conventional drugs or therapeutic agents suffer from nonspecificity of action, degradation of the drug before reaching the target site (low bioavailability or failure to traverse the blood-brain barrier), and poor solubility in the delivery medium. Drug intercalation with nanoparticles improves their efficacy by sustaining release and targeting the cell surface rising ligands connected with membrane disruption and endosomal uptake. They also permit drug release in the cell cytoplasm and shield the drug from enzymatic degradation. ${ }^{26-28}$ Use of inorganic nanoparticles in nanodrug development has gained considerable acceptance in recent times, due to their versatile features such as good biocompatibility, wide availability, rich surface functionality, and prospective capability of drug delivery. ${ }^{29-32}$
Intercalation of an active compound into inorganic nanoparticles such as zinc layered hydroxide (ZLH) has been successful due to the anionic exchange capacity of the nanocarrier. Apart from CA, many compounds of pharmacological importance have been successfully loaded into ZLH. These include gallic acid, ${ }^{33,34}$ nucleoside monophosphate, DNA, ${ }^{35,36}$ linoleic acid, ${ }^{37}$ and sunscreen materials such as 4-amino benzoic acid..$^{38,39}$ This study was designed to determine the effect of intercalation on the anti-inflammatory potential of $\mathrm{CA}$ by evaluating the production and expression of various inflammatory mediators, ie, NO, PGE 2 , TNF- $\alpha$, IL-6, IL-1 $\beta$, IL-10, cyclooxygenase-2 (COX-2), inducible NO synthase (iNOS), and nuclear factor kappa B (NF-кB), in lipopolysaccharide (LPS) stimulated RAW 264.7 macrophages.

\section{Materials and methods Materials}

The RAW 264.7 cell line was sourced from the American Type Culture Collection (ATCC, Manassas, VA, USA), cultured and maintained in Dulbecco's modified Eagle's medium, and supplemented with $10 \%$ fetal bovine serum and $1 \%$ antibiotics. LPS and dexamethasone were sourced from Nacalai Tesque Inc (Tokyo, Japan). CA was supplied by Acros (Geel, Belgium), while ZLH and cinnamate-ZLH (ZCA) were synthesized and characterized in the Institute of Advanced Technology, Universiti Putra Malaysia. ${ }^{39}$ $\mathrm{PGE}_{2}$ and an enzyme-linked immunosorbent assay kit were purchased from R\&D Systems (Minneapolis, MN, USA). All Western blotting apparatus and reagents were from BioRad (St Louis, MO, USA). The primary antibodies iNOS, COX-2, NF- $\kappa \mathrm{B}$, and appropriate secondary antibodies (goat anti-rabbit and goat anti-mouse) were purchased from Santa Cruz Biotechnology (Dallas, TX, USA). Enhanced chemiluminescence substrates were manufactured by Nacalai Tesque Inc, while the polyvinylidene fluoride membrane was from Bio-Rad.

\section{Synthesis of nanocomposite and characterization}

ZLH and ZCA were synthesized and characterized in the Institute of Advance Technology, Universiti Putra Malaysia. ZLH was synthesized by a conventional coprecipitation method using aqueous solutions of zinc nitrate hexahydrate. ${ }^{40}$ $\mathrm{ZnO}$ was used as the parent material in the synthesis of ZCA through a newly developed direct method. ${ }^{39}$ Hydrolysis of $\mathrm{ZnO}$ formed a layer of $\mathrm{Zn}(\mathrm{OH})_{2}$, while the reaction of $\mathrm{Zn}$ ion species, hydroxyls, water, and cinnamate anions in the solution generated ZCA. Basal spacing of the nanocomposite 
obtained from power X-ray diffraction was $23.9 \AA$ following intercalation of cinnamate between the interlayer spaces of ZLH. Fourier transform infrared analysis showed that the nanocomposite possesses the absorption characteristics of both ZLH and pure CA. However, elemental analysis showed that $40.4 \% \mathrm{w} / \mathrm{w}$ of CA was contained in the nanohybrid, and the intercalated compound exhibited excellent ultraviolet $\mathrm{A}$ and $\mathrm{B}$ capacity. $\mathrm{ZnO}$ exhibited a slow absorption rate, reaching an optimal uptake at $8 \mathrm{~cm}^{3} / \mathrm{g}$, but after intercalating CA into ZLH layers, the adsorption uptake reached $37 \mathrm{~cm}^{3} / \mathrm{g}$. In addition, various types of medium were used to show slow and saturated release at low concentrations as evidence of retention of cinnamate in the ZLH interlayers. The resultant ZCA was found to be an effective and safe sunscreen agent. ${ }^{39}$

\section{Cell viability assay}

Cell viability was determined by the ability of mitochondrial reductase to convert 3-(4,5-dimethythiazol-2-yl)-2, 5-diphenyl tetrazolium bromide) (MTT) to formazan dye. Overnight culture of RAW 264.7 cells in 96-well plates was done at a density of $1.5 \times 10^{4}$ cells $/ 100 \mu \mathrm{L}$ in each well. This was followed by treating the cells with ZCA, CA, and ZLH for 24 hours, after which $10 \mu \mathrm{L}$ of MTT at a concentration of $5 \mathrm{mg} / \mathrm{mL}$ was added to each well and kept in a $5 \% \mathrm{CO}_{2}$ incubator for 4 hours at $37^{\circ} \mathrm{C}$. The MTT solution was then removed and $100 \mu \mathrm{L}$ of dimethyl sulfoxide was added to each well to lyse the cells. A Lambda 35 microplate reader (Perkin-Elmer, Boston, MA, USA) was used to measure absorbance at $570 \mathrm{~nm}$.

\section{Determination of NO production}

RAW 264.7 cells were seeded in 24-well culture plates at a density of $2 \times 10^{5}$ cells/well in $1 \mathrm{~mL}$ of culture medium followed by overnight incubation. Confluent cells were treated with varying concentrations of ZCA, CA, and ZLH (2.5, 5 and $10 \mu \mathrm{g} / \mathrm{mL}$ ) for one hour. The cells were then challenged with a $1 \mu \mathrm{g} / \mathrm{mL}$ concentration of LPS and incubated for a further 24 hours. Accumulated nitrite in the culture medium was measured as a representative of NO production using Griess reagent $(0.1 \% \mathrm{~N}-1$-[naphthyl] ethylenediamine dihydrochloride and $1 \%$ sulphanilamide and $5 \% \mathrm{H}_{3} \mathrm{PO}_{4}$ ). Next, $100 \mu \mathrm{L}$ of cell supernatant and an equal amount of Griess reagent were plated in each well of a 96-well plate. They were incubated for 10 minutes followed by absorbance reading at $550 \mathrm{~nm}$.

\section{Determination of cytokine production}

The inhibitory effect of ZCA on the production of IL-6, IL-1 $\beta$, TNF- $\alpha$, and IL-10 were determined by enzyme-linked immunosorbent assay using medium collected from the treated cells. RAW 264.7 cells were seeded into a six-well plate at a density of $2 \times 10^{5}$ cells/well and incubated overnight. The cells were then treated with ZCA, CA, and ZLH (2.5, 5 and $10 \mu \mathrm{g} / \mathrm{mL}$ ) for one hour. This was followed with addition of $1 \mu \mathrm{g} / \mathrm{mL}$ LPS for 24 hours to induce inflammation. Culture supernatants were assayed according to the protocol of the enzyme-linked immunosorbent assay kit (R\&D Systems) to measure the amount of IL-6, IL-1 $\beta$, TNF- $\alpha$, and IL-10 produced in each sample. The experiment was carried out in triplicate.

\section{Determination of $\mathrm{PGE}_{2}$ level}

RAW 264.7 cells plated at a density of $2 \times 10^{5}$ in six-well plates were incubated overnight. Confluent cells were then treated with ZCA, CA, or ZLH at concentrations of 2.5, 5, and $10 \mu \mathrm{g} / \mathrm{mL}$ for one hour, followed by induction of inflammation with LPS for another 24 hours. The concentration of $\mathrm{PGE}_{2}$ was determined using a $\mathrm{PGE}_{2}$ immunoassay kit (R\&D Systems) according to the manufacturer's guidelines.

\section{Western blot analysis}

Confluent RAW 264.7 cells were treated with ZCA, CA, or ZLH $(2.5,5$, and $10 \mu \mathrm{g} / \mathrm{mL})$ for one hour and then challenged with LPS $1 \mu \mathrm{g} / \mathrm{mL}$ for 24 hours. Thereafter, the cells were scraped and centrifuged at 1,200 rpm for 10 minutes at $4^{\circ} \mathrm{C}$. The supernatant was discarded, and phosphate-buffered saline was added followed by centrifugation at 1,200 rpm for 10 minutes at $4^{\circ} \mathrm{C}$. Ice-cold cell lysis buffer were added to the cells for 30 minutes with intermittent shaking. Finally, the cells were centrifuged at 14,000 rpm for 30 minutes at $4^{\circ} \mathrm{C}$. Protein concentrations in the samples were estimated using a bicinchoninic acid protein assay kit with bovine serum albumin as the standard. Total proteins $(20 \mu \mathrm{g})$ were separated by sodium dodecyl sulfate polyacrylamide gel electrophoresis (SDS-PAGE) using 10\% polyacrylamide gel and transferred to a polyvinylidene fluoride membrane. Blocking was done with 5\% skimmed milk in PBST (1\% v/v Tween-20 in phosphate-buffered saline, $\mathrm{pH}$ 7.2) for one hour. The membranes were thereafter incubated with anti-mouse iNOS, anti-mouse NF- $\kappa$ B, and anti-mouse COX-2 (Santa Cruz Biotechnology) in a $1: 1,000$ concentration at $4^{\circ} \mathrm{C}$ overnight. The membranes were then washed six times in PBST at regular intervals for one hour. This was followed by incubation with horseradish peroxidase-conjugated goat anti-rabbit and goat anti-mouse, immunoglobulin $\mathrm{G}$ secondary antibodies (Santa Cruz Biotechnology) at a concentration of 1:2,000 for one hour. Membranes were finally washed six times in PBST for 10 minutes each. Chemiluminescence 
substrate (Thermo Scientific, Rockford, IL, USA) was used to reveal the blots detected with Chemidoc ${ }^{\mathrm{TM}}$ XRS (Bio-Rad). Intensity of the blots was finally analyzed using Bio-Rad Lab image software.

\section{Statistical analysis}

The statistical significance of differences between the various experimental values and control values was determined using the Student's $t$-test. The data are expressed as the mean \pm standard deviation, and the results were selected from at least three independent experiments performed in triplicate. $P$-values of 0.05 or less were considered to be statistically significant.

\section{Results}

\section{Effect of ZCA, CA, and ZLH on cell viability}

The cytotoxicity potential of compounds, ie, CA intercalated with ZLH (ZCA) which is the nanocomposite of interest, $\mathrm{CA}$ and the nanocarrier system, ZLH, were tested in RAW 264.7 cells. As shown in Figure 1, incubation of cells with ZCA showed a $40 \%$ reduction in cell viability at $40 \mu \mathrm{g} / \mathrm{mL}$, but cell viability was above $80 \%$ when ZCA $20 \mu \mathrm{g} / \mathrm{mL}$ was incubated with confluent cells. While coincubation of cells with $\mathrm{ZLH} 40 \mu \mathrm{g} / \mathrm{mL}$ yielded $53 \%$ cell viability, other concentrations showed more than $80 \%$ cell viability. However, CA did not display any toxicity even at $40 \mu \mathrm{g} / \mathrm{mL}$. Nevertheless, the three concentrations $(2.5,5.0$, and $10.0 \mu \mathrm{g} / \mathrm{mL})$ were chosen for subsequent assays and analysis.

\section{Effects of ZCA on LPS-induced NO production}

The inhibitory effect of ZCA on the production of NO was investigated using LPS-activated RAW 264.7 macrophages.
Inhibition of $\mathrm{NO}$ by ZCA occurred in a dose-dependent manner $(47.66 \%, 52.52 \%$, and $65.12 \%$ at $2.5,5$, and $10 \mu \mathrm{g} / \mathrm{mL}$, respectively, as shown in Figure 2). The activity displayed by CA was lower than that of ZCA when the compound was incubated with LPS-stimulated RAW 264.7 macrophages. CA achieved 36.31\%, 39.198\%, and 53.27\% inhibition of NO production at $2.5,5$, and $10 \mu \mathrm{g} / \mathrm{mL}$, respectively. ZLH did not show any significant inhibitory activity. However, dexamethasone, which served as the positive control, was found to inhibit the production of NO by $86.24 \%$.

\section{Effect of ZCA on $\mathrm{PGE}_{2}$ biosynthesis}

The downregulatory activity of ZCA on production of the proinflammatory marker $\mathrm{PGE}_{2}$ was investigated using LPSactivated RAW 264.7 cells. Enzyme-linked immunosorbent assay results showed a significant increase in levels of $\mathrm{PGE}_{2}$ in the culture supernatants of RAW 264.7 cells stimulated with LPS $(7,611.62 \mathrm{pg} / \mathrm{mL})$ compared with nonstimulated cells $(197.65 \mathrm{pg} / \mathrm{mL})$. Addition of ZCA to the mixture significantly inhibited the production of $\mathrm{PGE}_{2}$ at different concentrations, as shown in Figure 3. The activity of ZCA in samples treated with $10.0 \mu \mathrm{g} / \mathrm{mL}$ was the highest, ie, $89.98 \%$ (762.34 pg/mL) inhibition $(P<0.01)$, while inhibition was $53.14 \%(3,566.70 \mathrm{pg} / \mathrm{mL})$ at $5 \mu \mathrm{g} / \mathrm{mL}$ and $48.35 \%$ $(3,931.35 \mathrm{pg} / \mathrm{mL})$ at $2.5 \mu \mathrm{g} / \mathrm{mL}$. CA showed comparatively lower effects, ie, $10.65 \%(6,800.70 \mathrm{pg} / \mathrm{mL}), 20.16 \%$ $(6,077.59 \mathrm{pg} / \mathrm{mL})$, and $57.73 \%(3,069.84 \mathrm{pg} / \mathrm{mL})$ inhibition at $2.5,5.0$, and $10.0 \mu \mathrm{g} / \mathrm{mL}$, respectively. ZLH exhibited the lowest inhibitory activity, ie, $0.78 \%(7,551.19 \mathrm{pg} / \mathrm{mL})$, $3.50 \%(7,345.56 \mathrm{pg} / \mathrm{mL})$, and $2.27 \%(7,438.53 \mathrm{pg} / \mathrm{mL})$. The inhibitory effect of the positive control drug, dexamethasone, was $49.94 \%(3,760.05 \mathrm{pg} / \mathrm{mL})$.

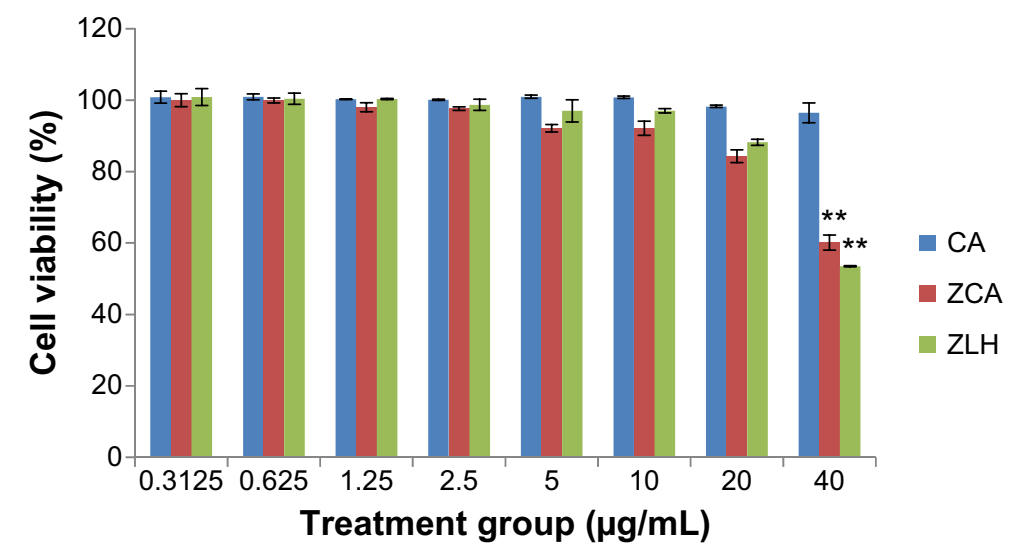

Figure I Viability of RAW 264.7 cells after 24 hours of treatment with ZCA, CA, and ZLH.

Notes: The data are presented as the mean \pm standard deviation of three independent experiments. $* * P<0.0$ I versus untreated lipopolysaccharide-stimulated group. Abbreviations: CA, cinnamic acid; ZCA, cinnamate-zinc layered hydroxide; $\mathrm{ZLH}$, zinc layered hydroxide. 


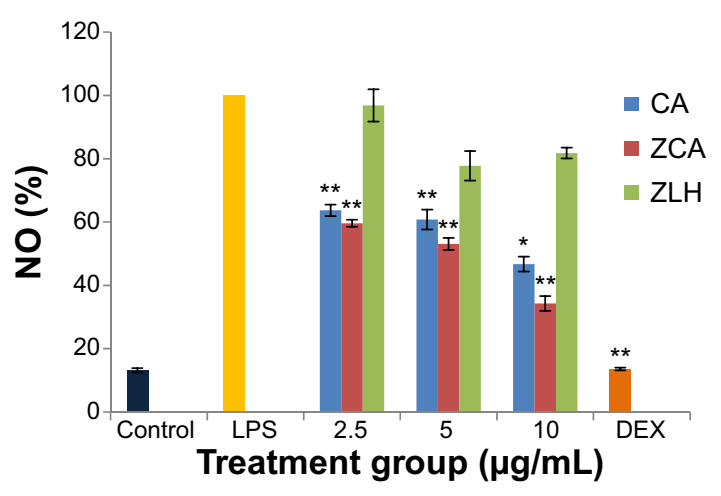

Figure 2 Inhibitory effects of ZCA on LPS-induced NO production in RAW 264.7 macrophages.

Notes: Production of $\mathrm{NO}$ was assayed in the culture medium of macrophages pretreated with ZCA, CA, and ZLH $(2.5,5$, and $10 \mu \mathrm{g} / \mathrm{mL}$, respectively) and later stimulated with LPS $(I \mu \mathrm{g} / \mathrm{mL})$ for 24 hours. Each value indicates the mean \pm standard deviation of three independent experiments. $* P<0.05$, $* * P<0.0$ l versus untreated LPS-stimulated group.

Abbreviations: CA, cinnamic acid; LPS, lipopolysaccharide; NO, nitric oxide; ZCA cinnamate-zinc layered hydroxide; ZLH, zinc layered hydroxide; DEX, dexamethasone.

\section{Effect of ZCA on LPS-induced production of proinflammatory cytokines}

The concentrations of IL-6, TNF- $\alpha$, and IL-1 $\beta$ (suggestive of proinflammatory cytokine activity) and IL-10 (suggestive of anti-inflammatory activity) in the treated RAW 264.7 cells are shown in Figure 4A-D, respectively. The results indicate that concurrent ZCA or CA treatment with LPS-stimulated cells significantly inhibited levels of IL-6, TNF- $\alpha$, and IL-1 $\beta$. Although production of IL- 6 was reduced by both ZCA and $\mathrm{CA}$ in a similar manner, the inhibitory activity of ZCA in the synthesis of TNF- $\alpha$ was comparatively higher. While

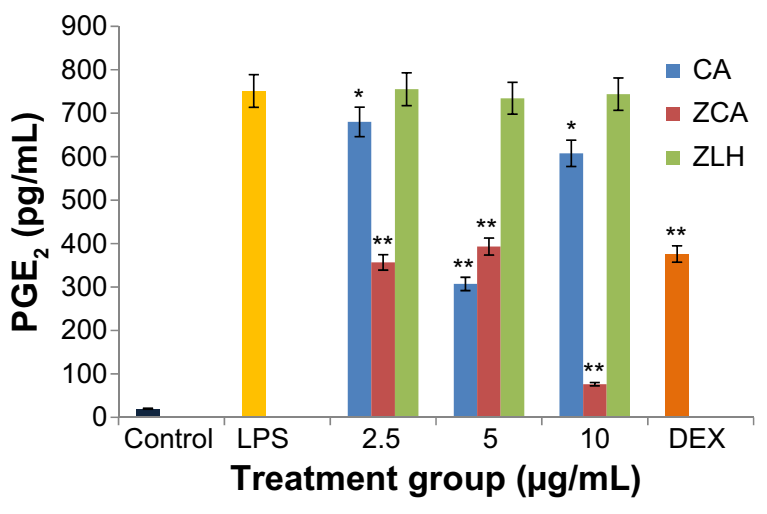

Figure 3 Inhibitory effect of ZCA on LPS-induced production of PGE $E_{2}$ in RAW 264.7 macrophages.

Notes: Production of PGE $E_{2}$ was assayed according to an enzyme-linked immunosorbent assay protocol, using the culture medium of confluent cells pretreated with ZCA, CA, and ZLH $(2.5,5$, and $10 \mu \mathrm{g} / \mathrm{mL}$, respectively) and later stimulated with LPS $(I \mu \mathrm{g} / \mathrm{mL})$ for 24 hours. Each value indicates the mean \pm standard deviation of three independent experiments. $* P<0.05$ and $* * P<0.01$ versus untreated LPS-stimulated group.

Abbreviations: CA, cinnamic acid; DEX, dexamethasone; LPS, lipopolysaccharide; $\mathrm{PGE}_{2}$, prostaglandin $\mathrm{E}_{2}$; ZCA, cinnamate-zinc layered hydroxide; $Z \mathrm{LH}$, zinc layered hydroxide.
CA exhibited $15.60 \%, 15.83 \%$, and $19.96 \%$ inhibition at $2.5,5$ and $10 \mu \mathrm{g} / \mathrm{mL}$, respectively, ZCA inhibited TNF- $\alpha$ production by more than $40 \%$ in all treatments. The highest augmentation of IL-1 $\beta$ inhibition was observed in samples treated with ZCA at a concentration of $10 \mu \mathrm{g} / \mathrm{mL}$. Although inhibitory activity of ZLH was not significant when compared with nanocomposite, ZCA and free drug CA.

In the case of anti-inflammatory cytokine activity, ZCA treatment potentiated a significant rise in levels of IL-10 in RAW 264.7 macrophages. In comparison with LPS-stimulated groups, ZCA treated samples were highly significant $(P<0.01)$, with $17.17 \%$ upregulation at $10 \mu \mathrm{g} / \mathrm{mL}$, while its activity at 2.5 and $5 \mu \mathrm{g} / \mathrm{mL}$ was less significant $(P<0.05)$, with upregulation of $8.31 \%$ and $8.43 \%$, respectively. Although CA upregulated the IL-10 cytokine at all three concentrations applied, the effect of CA was not significant when compared with samples stimulated with LPS alone. In contrast, treatment with ZLH did not improve production of IL-10.

\section{Effects of ZCA on LPS-induced COX-2, iNOS and NF- $\kappa B$ expression}

The effect of ZCA on the protein expression of iNOS, COX-2, and NF-KB was investigated using LPS-induced RAW 264.7 macrophages. From the Western blotting data shown in Figure 5, nonstimulated RAW 264.7 cells lacked iNOS activity. When the cells were induced with LPS, some level of iNOS expression was observed. On the other hand, expression of iNOS protein was significantly reduced by ZCA and CA when incubated with LPS-stimulated RAW 264.7 cells.

Additionally, while COX-2 was hardly detected in nonstimulated cells, high expression of the enzyme was observed on Western blotting analysis in samples treated with ZLH at 5.0 and $10.0 \mu \mathrm{g} / \mathrm{mL}$ (Figure 5). Both ZCA and CA exhibited low expression of COX-2 in contrast with the expression observed in samples treated with LPS alone. RAW 264.7 cells incubated with LPS alone showed a high intensity of $\mathrm{NF}-\mathrm{\kappa B}$, while samples pretreated with ZCA and CA before LPS stimulation showed downregulated expression of NF- $\kappa B$. Although CA inhibited NF- $\mathrm{KB}$ to a better extent than the intercalated compound, the activities of the two compounds were highly significant $(P<0.01)$, as shown in the analysis. Again, high expression of NF- $\mathrm{KB}$ was observed in samples treated with the nanocarrier, ZLH. Nevertheless, dexamethasone inhibited NF- $\mathrm{KB}$ in a manner comparable with that of CA.

\section{Discussion}

The role of macrophages in many inflammatory processes highlights their importance in both innate and adaptive 

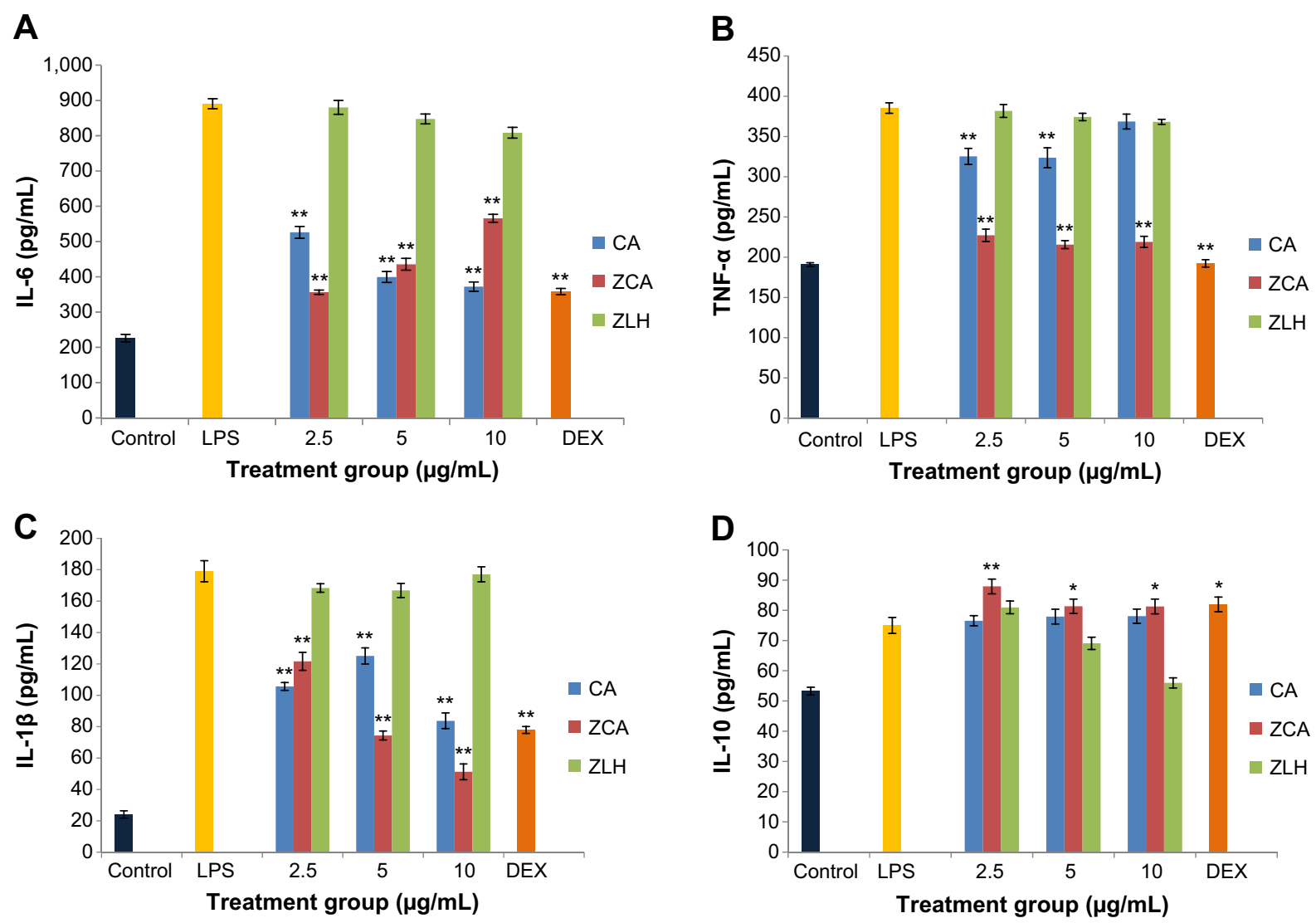

Figure 4 (A-D) Effect of ZCA on IL-6, TNF- $\alpha$, IL-I $\beta$, and IL-10 production in LPS stimulated RAW 264.7 macrophages.

Notes: Production of cytokines was assayed according to an enzyme-linked immunosorbent assay protocol using the culture supernatant of macrophages pretreated with ZCA, CA, and ZLH $(2.5,5$, and $10 \mu \mathrm{g} / \mathrm{mL})$ and later stimulated with LPS $(1 \mu \mathrm{g} / \mathrm{mL})$ for 24 hours. Each value indicates the mean \pm standard deviation of three independent experiments. $* P<0.05, * * P<0.01$ versus untreated LPS-stimulated group.

Abbreviations: CA, cinnamic acid; DEX, dexamethasone; IL, interleukin; LPS, lipopolysaccharide; TNF- $\alpha$, tumor necrosis factor alpha; ZCA, cinnamate-zinc layered hydroxide; ZLH, zinc layered hydroxide.

immunity. ${ }^{41,42}$ Macrophages are associated with many disease conditions, such as inflammation, infection, atherosclerosis, lupus, cancer, and diabetes. ${ }^{43}$ In this study, the RAW 264.7 macrophage was selected to evaluate the potential of CA-ZLH intercalation to improve the anti-inflammatory properties of CA. Some recent studies have reported the anti-inflammatory activity of CA. ${ }^{44}$ However, its effect on the production of NO, $\mathrm{PGE}_{2}$, and cytokines in LPS-stimulated RAW 264.7 cells is yet to be reported. Apart from a report on the potential of ZCA as a sunscreen agent with an ultraviolet protection effect, ${ }^{39}$ there is no report on the anti-inflammatory activity of the nanocomposite (ZCA) in LPS-induced inflammation.

The LPS endotoxin triggers an extensive injury to the macrophage. Apart from a reduced capacity to produce antigen, synthesis of important mediators, such as reactive oxygen species, free radicals, cytokines, and bioactive lipids, are altered. ${ }^{45-47}$ In recent times, treatment of inflammatory disorders has been largely based on inhibiting the action or synthesis of important mediators that prompt the host's response to attack. Many therapeutic agents, such as nonsteroidal anti-inflammatory drugs, steroids, and histamine, were developed based on this strategy. Data acquired from the assays undertaken in this research confirm that LPS endotoxin activates significant production of $\mathrm{NO}$, $\mathrm{PGE}_{2}$, and inflammatory cytokines (IL-6, TNF- $\alpha, \mathrm{IL}-1 \beta$ ), in RAW 264.7 cells.

However, the data reported in the previous sections show the enhanced anti-inflammatory potential of the ZCA nanocomposite when compared with CA. Synthesis of ZCA involved loading of only $40.4 \%$ of CA between the ZLH interlayers, but ZCA reduced the production of inflammatory markers in a manner comparable with that of the positive control. Samples treated with ZCA at all concentrations showed low levels of NO, providing clear evidence that the intercalation enhanced the anti-inflammatory activity of CA. The inhibitory effect of ZCA on production of NO may be associated with downregulation of iNOS expression by the same compound (Figure 5). NO production is strongly linked with the continuous synthesis of iNOS, which breaks down arginine to NO and citrulline. Increased NO production is 

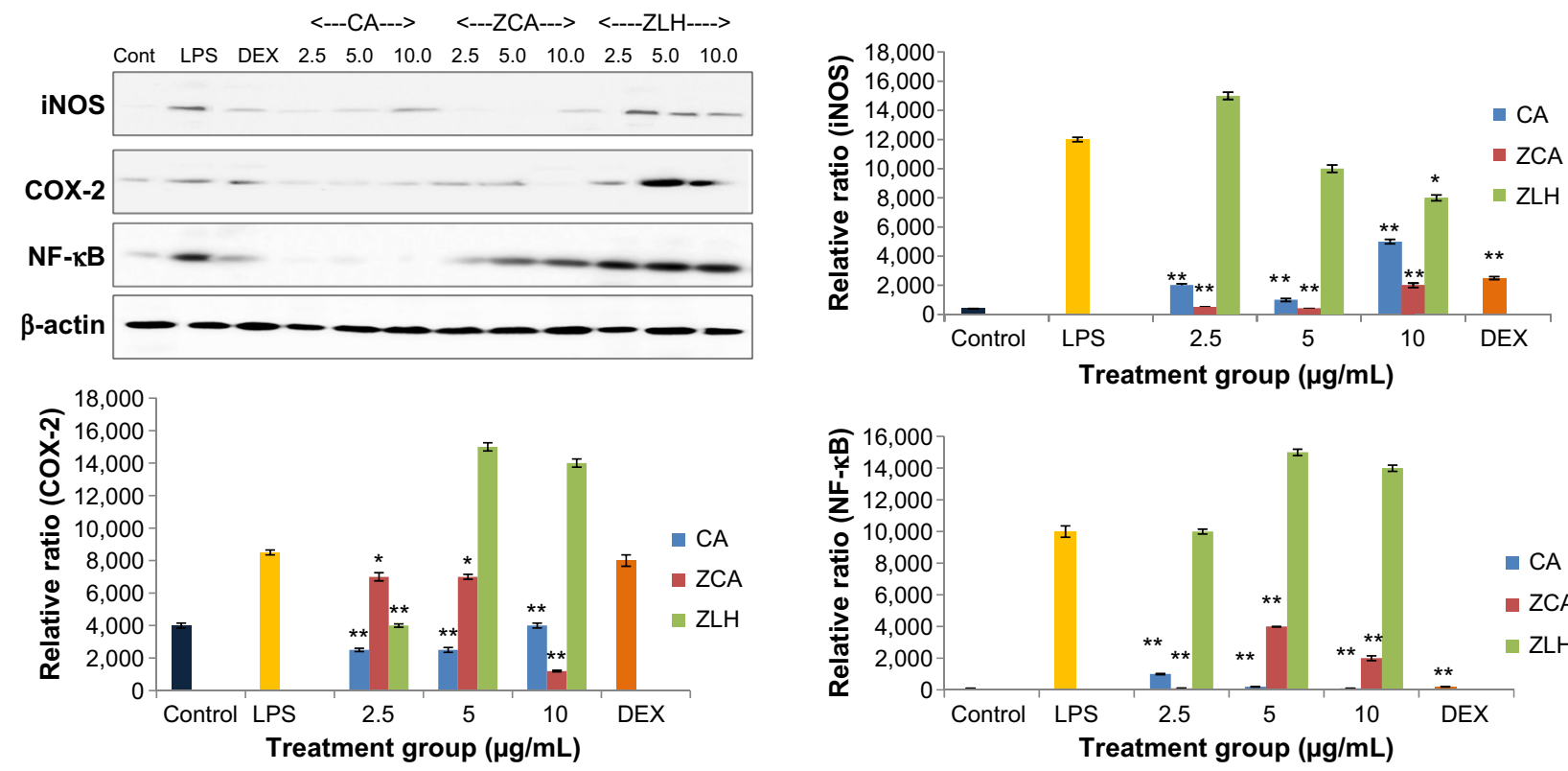

Figure 5 Inhibitory effect of ZCA on LPS-induced iNOS, COX-2, and NF- $\kappa B$ expression in LPS stimulated RAW 264.7 macrophages.

Notes: RAW 264.7 macrophage cells were pretreated with ZCA, CA, and ZLH $(2.5,5$, and $10 \mu \mathrm{g} / \mathrm{mL})$ for one hour. The cells were then challenged with LPS I $\mu \mathrm{gg} / \mathrm{mL}$ for

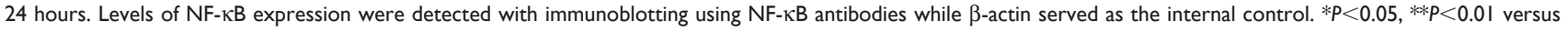
untreated LPS-stimulated group.

Abbreviations: CA, cinnamic acid; Cont, control; COX-2, cyclooxygenase-2; DEX, dexamethasone; iNOS, inducible nitric oxide synthase; LPS, lipopolysaccharide; NF-KB, nuclear factor kappa B; ZCA, cinnamate-zinc layered hydroxide; ZLH, zinc layered hydroxide.

observed in various diseases, and NO synthase inhibitors have successfully reversed many classic signs and symptoms of inflammation. ${ }^{48,49}$ Mulligan et al, using experimental rats with immune complex-induced lung injury, found that inhibitors of NO synthesis have protective properties in this model. ${ }^{50}$ In contrast, L-arginine, which is a precursor of NO, complicates tissue injury. Similarly, the effect of inflammatory bowel disease was reduced in experimental animals with induced colitis by administration of two different NO synthase inhibitors, ie, N-nitro-L-arginine methyl ester and aminoguanidine. ${ }^{48,49}$ Therefore, any compound that is capable of inhibiting iNOS, like ZCA, may be a potential anti-inflammatory agent.

Further, the effect of ZCA in inhibiting production of $\mathrm{PGE}_{2}$ was not only significant at the lowest concentration but comparatively better than CA and even dexamethasone (Figure 3). COX-2 is a key mediator in the inflammatory process, and is responsible for production of $\mathrm{PGE}_{2}$ from arachidonic acid. Downregulation of COX-2 is therefore a condition for the inhibition of $\mathrm{PGE}_{2}$, which is expressed in all processes that lead to major signs of inflammation, ie, swelling, redness, and pain. ${ }^{51,52}$ Hence, in Figure 3 and Figure 5 there is a strong relationship between the activity of ZCA, where the expression of COX-2 was significantly inhibited by the nanocomposite. Administration of N-398, a COX-2 inhibitor, after treatment with carrageenan lowered the production of $\mathrm{PGE}_{2}$ and the same pattern was observed in COX-2 knockout mice. Deficiency of COX-2 was also observed to reduce $\mathrm{PGE}_{2}$ by $75 \%{ }^{53,54}$ The $\mathrm{COX}-2 / \mathrm{PGE}_{2}$ pathway is the major target for designing pain-relieving drugs for osteoarthritis, but most nonsteroidal anti-inflammatory drugs inhibit the activity of COX-1/COX-2, which may result in unwanted side effects. Limited side effects are some of the advantages of drugs such as celecoxib that exclusively target $\mathrm{COX}-2 .{ }^{55-57} \mathrm{ZCA}$ is a potential anti-inflammatory agent that can selectively block the synthesis of the inducible enzyme, COX-2.

The inhibitory effect of ZCA on the secretion of TNF- $\alpha$ in Figure 4B and a similar downregulation of IL-1 $\beta$ in Figure $4 \mathrm{C}(5.0 \mu \mathrm{g} / \mathrm{mL}$ and $10.0 \mu \mathrm{g} / \mathrm{mL})$ were better than with CA. The carrier system did not have any inhibitory effects on these cytokines, which dispels any possibility of ZLH contributing to the anti-inflammatory activity of ZCA. Proinflammatory cytokines like TNF- $\alpha$, IL- $1 \beta$, and IL- 6 are small molecules that modulate inflammation and immunity. Bacterial LPS activates macrophages to secrete TNF- $\alpha$, and the released TNF- $\alpha$ or LPS then triggers production of IL-6 and IL- $1 \beta .{ }^{58,59}$ TNF- $\alpha$ induces many physiological changes, including inflammation, septic shock, and cytotoxicity. ${ }^{60}$ However, anti-TNF therapy triggers a rapid improvement in many serological parameters and histological characteristics of the synovium. ${ }^{61-63}$ Blockade of TNF- $\alpha$ activity has also been linked with improved survival in animal models of sepsis and shock. ${ }^{64-66}$ 
The inhibition of TNF- $\alpha$ and other cytokines may be connected with low expression of NF-KB in samples treated with ZCA and CA. as shown in Figure 5. NF- $\mathrm{KB}$ is a key transcription factor that coordinates the expression of proinflammatory cytokines and enzymes. ${ }^{7,67}$ Treatment with anti-TNF- $\alpha$ antibody after LPS activation inhibited TNF- $\alpha$ and NF- $\mathrm{KB}$ in an in vivo animal model; moreover, the kinetics of the NF- $\kappa B$ activation and TNF- $\alpha$ secretion triggered by LPS in this model were similar. ${ }^{68,69}$ This shows that any treatment that affects the expression of NF- $\mathrm{KB}$ is likely to influence the production of proinflammatory cytokines. Agents that block proximal cytokines such as TNF- $\alpha$ and IL- $1 \beta$ also restrict activation of NF- $\kappa B$, thereby inhibiting the inflammatory cascade..$^{70,71}$

It has been established that IL-10 influences the inflammatory process by suppressing inflammatory mediators, including proinflammatory cytokines, adhesion molecules, and antigen-presenting molecules in neutrophils, monocytes/ macrophages, and T-cells. ${ }^{72,73} \mathrm{IL}-10$ blocks the expression of proinflammatory cytokines such as IL-6, TNF- $\alpha$, and IL-1 $\beta$ in activated macrophages. In specific terms, it upregulates other endogenous anticytokines and inhibits proinflammatory cytokine receptors..$^{59,74}$ Therefore, it can counter-regulate the release and roles of proinflammatory cytokines at multiple levels. Given that inflammatory proteins are transcriptionally regulated by NF- $\mathrm{KB}$, it has been proposed that IL-10 may express a major part of its anti-inflammatory activity by inhibiting the transcription factor. ${ }^{75-77}$ As a result, upregulation of IL-10 may be associated with inhibition of NF-KB by ZCA and CA.

$\mathrm{NF}-\mathrm{\kappa B}$ is known for its unique role in coordinating the immune and inflammatory responses. ${ }^{78}$ They are identifiable with the homodimer or heterodimer structure of the Rel proteins. In resting cells, NF- $\kappa B$ forms an inactive complex with inhibitory $\kappa \mathrm{B}(\mathrm{I} \kappa \mathrm{B})$ proteins like $\mathrm{I} \kappa \mathrm{B} \alpha$, I $\mathrm{\kappa} \mathrm{B} \beta$, and I $\mathrm{I} \mathrm{Be} .{ }^{79}$ Upon recognition of LPS by toll-like receptor-4 and MD2, its accessory protein attached to immune cells and activates

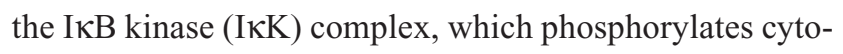
plasmic IKBs. ${ }^{80,81}$ Subsequently, ubiquitin-mediated degra-

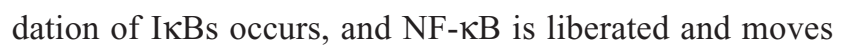
into the nucleus. The binding of NF- $\kappa B$ to the $\kappa B$ sequences regulates the transcription of immune and inflammatory genes such as COX-2, iNOS, and inflammatory cytokines (IL-6, IL-1 $\beta$, TNF- $\alpha$, IL-10). ${ }^{82}$ Since the expression levels of these proinflammatory mediators are regulated by NF- $\mathrm{\kappa B}$, our findings suggest that their production is transcriptionally inhibited by ZCA by blocking of the NF- $\mathrm{KB}$ signaling pathway.
Finally, findings from ELISA and western blot analysis revealed that ZLH exhibited a slight upregulation of inflammatory enzymes and NF- $\mathrm{KB}$ activation in LPS stimulated RAW cells. Although, ZLH has been found to have a low toxicity profile, studies have shown that some nanomaterials have the potential to stimulate inflammatory reactions. Notably, ZnO, which can serve as precursor for ZLH, has been reported to cause marginal production of IL- 6 and IL-8 in HK-2 and HEK 293 cells. Release of ions by $\mathrm{ZnO}$ materials has been proposed as the likely mechanism of cytotoxicity. ${ }^{39,83}$ Studies have also shown that nanoparticles generate reactive oxygen species through interaction with the plasma membrane, but the cell has a self-repair mechanism to maintain its integrity, and overexpression of inflammatory mediators may not be associated with production of reactive oxygen species. ${ }^{84}$ The increased level of inflammatory mediators beyond the negative control thresholds may be due to a synergistic action between LPS and ZLH. Nonetheless, ZLH on its own was not toxic at the doses applied.

\section{Conclusion}

The present study is an example of fundamental research towards developing ZCA as a strong anti-inflammatory nanomedicine. Our results suggest that ZCA has better inhibitory activity for LPS-stimulated proinflammatory mediators than that of the free drug, CA. Therefore, ZCA possess therapeutic potential for the regulation and modulation of macrophage activation, and may serve as effective alternative treatment for a number of inflammation-mediated diseases.

\section{Acknowledgment}

This research was supported by a grant from the Research Universiti Grant Scheme (GP/IPB/2013/9425802), Universiti Putra Malaysia, Selangor, Malaysia.

\section{Disclosure}

The authors report no conflicts of interest in this work.

\section{References}

1. Cook-Mills JM, Deem TL. Active participation of endothelial cells in inflammation. J Leukoc Biol. 2005;77(4):487-495.

2. Kvietys PR, Granger DN. Role of reactive oxygen and nitrogen species in the vascular responses to inflammation. Free Radic Biol Med. 2012;52(3):556-592.

3. Kaplanski G, Marin V, Montero-Julian F, Mantovani A, Farnarier C. IL-6: a regulator of the transition from neutrophil to monocyte recruitment during inflammation. Trends Immunol. 2003;24(1):25-29.

4. Lippitz BE. Cytokine patterns in patients with cancer: a systematic review. Lancet Oncol. 2013;14(6):e218-e228.

5. Medzhitov R, Janeway C Jr. Innate immunity. N Engl J Med. 2000;343(5): $338-344$. 
6. ElinavE, Strowig T, Kau AL, etal. NLRP6 inflammasome regulates colonic microbial ecology and risk for colitis. Cell. 2011;145(5):745-757.

7. Aderem A, Ulevitch RJ. Toll-like receptors in the induction of the innate immune response. Nature. 2000;406(6797):782-787.

8. van Eden W, Spiering R, Broere F, van der Zee R. A case of mistaken identity: HSPs are no DAMPs but DAMPERs. Cell Stress Chaperones. 2012;17(3):281-292.

9. Guzik TJ, Korbut R, Adamek-Guzik T. Nitric oxide and superoxide in inflammation. J Physiol Pharmacol. 2003;54(4):469-487.

10. Latham KA, Whittington KB, Zhou R, Qian Z, Rosloniec EF. Ex vivo characterization of the autoimmune T-cell response in the HLA-DR1 mouse model of collagen-induced arthritis reveals long-term activation of type II collagen-specific cells and their presence in arthritic joints. J Immunol. 2005;174(7):3978-3985.

11. Caudrillier A, Kessenbrock K, Gilliss BM, et al. Platelets induce neutrophil extracellular traps in transfusion-related acute lung injury. J Clin Invest. 2012;122(7):2661-2671.

12. Kasama T, Miwa Y, Isozaki T, Odai T, Adachi M, Kunkel SL. Neutrophil-derived cytokines: potential therapeutic targets in inflammation. Curr Drug Targets Inflamm Allergy. 2005;4(3):273-279.

13. Zawrotniak M, Rapala-Kozik M. Neutrophil extracellular traps (NETs) - formation and implications. Acta Biochim Pol. 2013;60(3): 277-284.

14. Zeilhofer HU, Brune K. Analgesic strategies beyond the inhibition of cyclooxygenases. Trends Pharmacol Sci. 2006;27(9):467-474.

15. Hwang SH, Wecksler AT, Wagner K, Hammock BD. Rationally designed multitarget agents against inflammation and pain. Curr Med Chem. 2013;20(13):1783-1799.

16. Heo SJ, Yoon WJ, Kim KN, et al. Evaluation of anti-inflammatory effect of fucoxanthin isolated from brown algae in lipopolysaccharidestimulated RAW 264.7 macrophages. Food Chem Toxicol. 2010; 48(8-9):2045-2051.

17. Kim ID, Ha BJ. Paeoniflorin protects RAW 264.7 macrophages from LPS-induced cytotoxicity and genotoxicity. Toxicol In Vitro. 2009; 23(6):1014-1019.

18. He ZD, Qiao CF, Han QB, et al. Authentication and quantitative analysis on the chemical profile of cassia bark (cortex cinnamomi) by high-pressure liquid chromatography. J Agric Food Chem. 2005; 53(7):2424-2428.

19. Sung YY, Yoon T, Jang JY, Park SJ, Jeong GH, Kim HK Inhibitory effects of Cinnamomum cassia extract on atopic dermatitis-like skin lesions induced by mite antigen in NC/Nga mice. J Ethnopharmacol. 2011;133(2):621-628

20. Liao JC, Deng JS, Chiu CS, et al. Anti-inflammatory activities of Cinnamomum cassia constituents in vitro and in vivo. Evid Based Complement Alternat Med. 2012;2012:429320.

21. Liu L, Hudgins WR, Shack S, Yin MQ, Samid D. Cinnamic acid: a natural product with potential use in cancer intervention. Int J Cancer. 1995;62(3):345-350.

22. Singh TS, Mitra S. Interaction of cinnamic acid derivatives with serum albumins: a fluorescence spectroscopic study. Spectrochim Acta A Mol Biomol Spectrosc. 2011;78(3):942-948.

23. Huang D-W, Szu-Chuan S. Caffeic acid and cinnamic acid ameliorate glucose metabolism via modulating glycogenesis and gluconeogenesis in insulin-resistant mouse hepatocytes. J Funct Foods. 2012;4(1):358-366.

24. Slowing II, Vivero-Escoto JL, Wu CW, Lin VS. Mesoporous silica nanoparticles as controlled release drug delivery and gene transfection carriers. Adv Drug Deliv Rev. 2008;60(11):1278-1288.

25. Colilla M, González B, Vallet-Regí M. Mesoporous silica nanoparticles for the design of smart delivery nanodevices. Biomater Sci. 2013;1(2):114-134.

26. Maeda H, Wu J, Sawa T, Matsumura Y, Hori K. Tumor vascular permeability and the EPR effect in macromolecular therapeutics: a review. $J$ Control Release. 2000;65(1-2):271-284.

27. Farokhzad OC, Langer R. Impact of nanotechnology on drug delivery. ACS Nano. 2009;3(1):16-20.
28. Kamaly N, Xiao Z, Valencia PM, Radovic-Moreno AF, Farokhzad OC Targeted polymeric therapeutic nanoparticles: design, development and clinical translation. Chem Soc Rev. 2012;41(7):2971-3010.

29. Barbe C, Bartlett J, Kong L, et al. Silica particles: a novel drug-delivery system. Adv Mater. 2004;16(21):1959-1966.

30. Bauer LA, Birenbaum NS, Meyer GJ. Biological applications of high aspect ratio nanoparticles. J Mater Chem. 2004;14(4):517-526.

31. Ozkan M. Quantum dots and other nanoparticles: what can they offer to drug discovery? Drug Discov Today. 2004;9(24):1065-1071.

32. Yang P, Gai S, Lin J. Functionalized mesoporous silica materials for controlled drug delivery. Chem Soc Rev. 2012;41(9):3679-3698.

33. Hussein MZ, Ghotbi MY, Yahaya AH, Rahman MZA. Synthesis and characterization of (zinc-layered-gallate) nanohybrid using structural memory effect. Mater Chem Phys. 2009;113(1):491-496.

34. Barahuie F, Hussein MZ, Fakurazi S, Zainal Z. Development of drug delivery systems based on layered hydroxides for nanomedicine. Int $J$ Mol Sci. 2014;15(5):7750-7786.

35. Choy JH, Kwak SY, Park JS, Jeong YJ, Portier J. Intercalative nanohybrids of nucleoside monophosphates and DNA in layered metal hydroxide. J Am Chem Soc. 1999;121(6):1399-1400.

36. Hussein Al Ali SH, Al-Qubaisi M, Hussein MZ, Ismail M, Zainal Z, Hakim MN. Comparative study of $\mathrm{Mg} / \mathrm{Al}$-and $\mathrm{Zn} / \mathrm{Al}$-layered double hydroxide-perindopril erbumine nanocomposites for inhibition of angiotensin-converting enzyme. Int J Nanomedicine. 2012;7:4251-4262.

37. Choy JH, Shin J, Lim SY, Oh JM, Oh MH, Oh S. Characterization and stability analysis of zinc oxide nanoencapsulated conjugated linoleic acid. J Food Sci. 2010;75(6):N63-N68.

38. Cursino AC, Gardolinski JE, Wypych F. Intercalation of anionic organic ultraviolet ray absorbers into layered zinc hydroxide nitrate. J Colloid Interface Sci. 2010;347(1):49-55.

39. Mohsin SM, Hussein MZ, Sarijo SH, Fakurazi S, Arulselvan P, Hin TY. Synthesis of (cinnamate-zinc layered hydroxide) intercalation compound for sunscreen application. Chem Cent J. 2013;7(1):26.

40. Saifullah B, Arulselvan P, El Zowalaty ME, et al. Development of a highly biocompatible antituberculosis nanodelivery formulation based on para-aminosalicylic acid-zinc layered hydroxide nanocomposites. Scientific World Journal. 2014;2014:401460.

41. Chou JJ, Li S, Klee CB, Bax A. Solution structure of Ca(2+)-calmodulin reveals flexible hand-like properties of its domains. Nat Struct Biol. 2001;8(11):990-997.

42. Sun YX, Minthon L, Wallmark A, Warkentin S, Blennow K, Janciauskiene S. Inflammatory markers in matched plasma and cerebrospinal fluid from patients with Alzheimer's disease. Dement Geriatr Cogn Disord. 2003;16(3):136-144.

43. Hagemann T, Biswas SK, Lawrence T, Sica A, Lewis CE. Regulation of macrophage function in tumors: the multifaceted role of NF-KB. Blood. 2009;113(14):3139-3146.

44. Liao JC, Deng JS, Chiu CS, et al. Anti-inflammatory activities of Cinnamomum cassia constituents in vitro and in vivo. Evid Based Complement Alternat Med. 2012;2012:429320.

45. Chou TC, Fu E, Shen EC. Chitosan inhibits prostaglandin E2 formation and cyclooxygenase-2 induction in lipopolysaccharide-treated RAW 264.7 macrophages. Biochem Biophys Res Commun. 2003;308(2):403-407.

46. Hussein H, Hussain H, Salbiah MS, Muhaini O, Low YL, Beh PK. Use of drugs for rheumatological and bone disorders. In: Faridah AM, Sivasampu S, Lian LM, Hazimah H, Kok LC, Chinniah RJ, editors. Malaysian Statistics on Medicines 2007. Kuala Lumpur, Malaysia: Ministry of Health Malaysia; 2010.

47. Kim ID, Ha BJ. Paeoniflorin protects RAW 264.7 macrophages from LPS-induced cytotoxicity and genotoxicity. Toxicol In Vitro. 2009;23(6):1014-1019.

48. Pilichos CJ, Kouerinis IA, Zografos GC, et al. The effect of nitric oxide synthases inhibitors on inflammatory bowel disease in a rat model. In Vivo. 2004;18(4):513-516.

49. Yang Y, Tomkovich S, Jobin C. Could a swimming creature inform us on intestinal diseases? Lessons from zebrafish. Inflamm Bowel Dis. 2014;20(5):956-966. 
50. Mulligan MS, Hevel JM, Marletta MA, Ward PA. Tissue injury caused by deposition of immune complexes is L-arginine dependent. Proc Natl Acad Sci USA. 1991;88(14):6338-6342.

51. Funk CD. Prostaglandins and leukotrienes: advances in eicosanoid biology. Science. 2001;294(5548):1871-1875.

52. Lee KW, Bode AM, Dong Z. Molecular targets of phytochemicals for cancer prevention. Nat Rev Cancer. 2011;11(3):211-218.

53. Langenbach R, Loftin $\mathrm{C}$, Lee $\mathrm{C}$, Tiano H. Cyclooxygenase knockout mice: models for elucidating isoform-specific functions. Biochem Pharmacol. 1999;58(8):1237-1246.

54. Ricciotti E, FitzGerald GA. Prostaglandins and inflammation. Arterioscler Thromb Vasc Biol. 2011;31(5):986-1000.

55. Mitchell JA, Akarasereenont P, Thiemermann C, Flower RJ, Vane JR. Selectivity of nonsteroidal antiinflammatory drugs as inhibitors of constitutive and inducible cyclooxygenase. Proc Natl Acad Sci U S A. 1993;90(24):11693-11697.

56. Jeffrey JE, Aspden RM. Cyclooxygenase inhibition lowers prostaglandin E2 release from articular cartilage and reduces apoptosis but not proteoglycan degradation following an impact load in vitro. Arthritis Res Ther. 2007;9(6):R129.

57. Mangal D, Uboh CE, Jiang Z, Soma LR. Interleukin- $1 \beta$ inhibits synthesis of 5-lipooxygenase in lipopolysaccharide-stimulated equine whole blood. Prostaglandins Other Lipid Mediat. 2014;108:9-22.

58. Beutler B, Cerami A. The common mediator of shock, cachexia, and tumor necrosis. Adv Immunol. 1988;42:213-231.

59. Zhang J-M, An J. Cytokines, inflammation and pain. Int Anesthesiol Clin. 2007;45(2):27-37.

60. Doufas AG, Tian L, Padrez KA, et al. Experimental pain and opioid analgesia in volunteers at high risk for obstructive sleep apnea. PLoS One. 2013;8(1):e54807.

61. Camussi G, Lupia E. The future role of anti-tumour necrosis factor (TNF) products in the treatment of rheumatoid arthritis. Drugs. 1998;55(5):613-620.

62. Singh J, Suruchi A. AntiTNF- $\alpha$ strategy: present status of this therapeutic paradigm. Indian J Pharmacol. 2004;36(1):10-14.

63. Appel E, Wallach D. Chimeric proteins, their preparation and pharmaceutical compositions containing them. US Patent 8,092,806, issued January 10, 2012.

64. Appoloni O, Dupont E, Vandercruys M, Andriens M, Duchateau J, Vincent JL. Association of tumor necrosis factor-2 allele with plasma tumor necrosis factor-alpha levels and mortality from septic shock. Am J Med. 2001;110(6):486-488.

65. Vincent JL. Afelimomab. Int J Clin Pract. 2000;54(3):190-193.

66. Zídek Z, Anzenbacher P, Kmonícková E. Current status and challenges of cytokine pharmacology. Br J Pharmacol. 2009;157(3):342-361.

67. Theoharides TC, Alysandratos KD, Angelidou A, et al. Mast cells and inflammation. Biochim Biophys Acta. 2012;1822(1):21-33.
68. Luo JL, Maeda S, Hsu LC, Yagita H, Karin M. Inhibition of NF- $\kappa B$ in cancer cells converts inflammation-induced tumor growth mediated by TNF $\alpha$ to TRAIL-mediated tumor regression. Cancer Cell. 2004;6(3): 297-305.

69. Ruffell B, Affara NI, Coussens LM. Differential macrophage programming in the tumor microenvironment. Trends Immunol. 2012;33(3):119-126.

70. Tak PP, Firestein GS. NF-кB: a key role in inflammatory diseases. $J$ Clin Invest. 2001;107(1):7-11.

71. DiDonato JA, Mercurio F, Karin M. NF- $\kappa B$ and the link between inflammation and cancer. Immunol Rev. 2012;246(1):379-400.

72. Moore KW, de Waal Malefyt R, Coffman RL, O'Garra A. Interleukin-10 and the interleukin-10 receptor. Annu Rev Immunol. 2001; 19:683-765.

73. Palucka K, Banchereau J. Cancer immunotherapy via dendritic cells. Nat Rev Cancer. 2012;12(4):265-277.

74. Kiguchi N, Kobayashi Y, Kishioka S. Chemokines and cytokines in neuroinflammation leading to neuropathic pain. Curr Opin Pharmacol. 2012;12(1):55-61.

75. Schottelius AJ, Mayo MW, Sartor RB, Baldwin AS Jr. Interleukin-10 signaling blocks inhibitor of $\mathrm{\kappa B}$ kinase activity and nuclear factor $\mathrm{\kappa B}$ DNA binding. J Biol Chem. 1999;274(45):31868-31874.

76. Hoentjen F, Sartor RB, Ozaki M, Jobin C. STAT3 regulates $\mathrm{NF}-\kappa \mathrm{B}$ recruitment to the IL-12p40 promoter in dendritic cells. Blood. 2005;105(2):689-696.

77. Osborn O, Olefsky JM. The cellular and signaling networks linking the immune system and metabolism in disease. Nat Med. 2012;18(3):363-374.

78. O'Sullivan B, Thompson A, Thomas R. NF- $\kappa \mathrm{B}$ as a therapeutic target in autoimmune disease. Expert Opin Ther Targets. 2007; 11(2):111-122.

79. Baeuerle PA, Baltimore D. I kappa B: a specific inhibitor of the NFkappa B transcription factor. Science. 1988;242(4878):540-546.

80. Zandi E, Chen Y, Karin M. Direct phosphorylation of I $\kappa$ B by IKK $\alpha$ and IKK $\beta$ : discrimination between free and NF- $\kappa \mathrm{B}-$ bound substrate. Science. 1998;281(5381):1360-1363.

81. Nagai Y,Akashi S, Nagafuku M, etal. Essential role of MD-2 in LPS responsiveness and TLR4 distribution. Nat Immunol. 2002;3(7):667-672.

82. Tian B, Brasier AR. Identification of a nuclear factor kappa B-dependent gene network. Recent Prog Horm Res. 2003;58:95-130.

83. Kermanizadeh A, Vranic S, Boland S, et al. An in vitro assessment of panel of engineered nanomaterials using a human renal cell line: cytotoxicity, pro-inflammatory response, oxidative stress and genotoxicity. BMC Nephrol. 2013;14:96.

84. Fröhlich E. The role of surface charge in cellular uptake and cytotoxicity of medical nanoparticles. Int J Nanomedicine. 2012;7:5577.
Drug Design, Development and Therapy

\section{Publish your work in this journal}

Drug Design, Development and Therapy is an international, peerreviewed open-access journal that spans the spectrum of drug design and development through to clinical applications. Clinical outcomes, patient safety, and programs for the development and effective, safe, and sustained use of medicines are a feature of the journal, which
Dovepress

has also been accepted for indexing on PubMed Central. The manuscript management system is completely online and includes a very quick and fair peer-review system, which is all easy to use. Visit http://www.dovepress.com/testimonials.php to read real quotes from published authors. 